\title{
La cooperación financiera internacional frente a la crisis económica latinoamericana ${ }^{1}$
}

\author{
José Antonio Ocampo
}

\section{Resumen}

La crisis económica en curso será recordada, no solo por ser la peor desde la Gran Depresión, sino también por la limitada cooperación financiera multilateral acordada, en particular para las economías de renta media. Varios países latinoamericanos se han beneficiado de las líneas de crédito flexible y de emergencia del Fondo Monetario Internacional (FMI), y pueden usar otras de sus herramientas. Los miembros del Fondo Latinoamericano de Reservas (FLAR) pueden acceder a sus recursos. Los bancos multilaterales de desarrollo adoptaron medidas para apoyar a los países latinoamericanos, pero los recursos son limitados. El Banco Interamericano de Desarrollo (BID) y el Banco de Desarrollo de América Latina (CAF) están en su límite de capacidad crediticia y necesitan capitalización. El Banco Mundial aumentó sus créditos a la región, pero son menores a los de 2009-2010. Se destaca la dinámica del Banco Centroamericano de Integración Económica (BCIE), gracias a su reciente capitalización.

\section{Palabras clave}

Crisis económica, instituciones financieras internacionales, bancos de desarrollo, cooperación internacional, deuda externa, América Latina

\section{Clasificación JEL}

$$
\text { F34, F55, G15, O19 }
$$

\section{Autor}

José Antonio Ocampo es Profesor de la Escuela de Asuntos Internacionales y Públicos de la Universidad de Columbia (Estados Unidos). Fue Secretario General Adjunto de Asuntos Económicos y Sociales de las Naciones Unidas, Secretario Ejecutivo de la Comisión Económica para América Latina y el Caribe (CEPAL) y Ministro de Hacienda de Colombia. Correo electrónico: ocampo.joseantonio@yahoo.com.

\footnotetext{
1 Este ensayo fue preparado para el Programa de las Naciones Unidas para el Desarrollo (PNUD) y publicado en COVID-19 Serie de Documentos de Política Pública (PNUD LAC C19 PDS N 7). Aquí se publica en una versión actualizada y un poco más breve. Dada la velocidad de los acontecimientos actuales, debe analizarse a la luz de la información y las decisiones de política adoptadas hasta el 1 de junio de 2020. Agradezco a Marcela Meléndez y Miguel Ángel Torres por sus comentarios a versiones previas, y a María Luisa Montalvo y Víctor Alejandro Ortega por la colaboración en su elaboración.
} 


\section{Introducción}

La pandemia del coronavirus (COVID-19), la peor en un siglo, ha generado una crisis económica mundial que ha sido caracterizada por la Directora Gerente del Fondo Monetario Internacional (FMI) como la peor desde la Gran Depresión de los años treinta del siglo pasado (Georgieva, 2020). Las medidas de confinamiento, adoptadas para gestionar los problemas de salud pública, han tenido profundos efectos económicos, ya que se han paralizado las actividades "no esenciales", que pueden representar el 50\% o más de la actividad económica en muchos países. La perturbación en los mercados financieros ha sido también profunda y generó la peor fuga de la historia de capitales de cartera desde las economías emergentes, aunque se observa una recuperación reciente. A su vez, el comercio internacional ha sufrido una marcada contracción, que profundiza el proceso iniciado a fines de 2019 como consecuencia de la desaceleración económica mundial y de las "guerras comerciales", especialmente entre los Estados Unidos y China. A esto se agrega la caída de los precios de un grupo importante de productos básicos, que se suma a la tendencia negativa observada desde hace un lustro. La exportación de servicios también ha disminuido, especialmente por la paralización del turismo y del tráfico aéreo de pasajeros. Las remesas de trabajadores migrantes a sus países de origen también sufrirán una reducción considerable y se están imponiendo nuevos controles a la migración internacional.

En caso de América Latina, la pandemia llegó con rezago, pero comenzó a tener efectos marcados en términos de personas afectadas y mortalidad en varios países, especialmente en el Brasil². En términos económicos, la pandemia golpeó a la región después de cinco años de lento crecimiento económico, que pueden caracterizarse como una "media década perdida" (Ocampo, 2020). Aparte de los efectos directos de las medidas de confinamiento decretadas en varios países, o las que la población ha adoptado voluntariamente para protegerse, las economías de la región también están sufriendo los efectos de la crisis mundial. América Latina tendrá la caída más pronunciada de la actividad económica en el mundo en desarrollo, reiterando el patrón que la ha caracterizado en décadas recientes, aunque con efectos heterogéneos en los distintos países. La recesión de 2020 será, además, la peor desde la Segunda Guerra Mundial, con lo cual existe el peligro (y casi la certeza) de que la media década perdida se transforme en una nueva década perdida.

En este contexto desfavorable, la cooperación económica internacional ha sido muy débil hasta ahora, en contraste con la intensa colaboración multilateral liderada por el Grupo de los 20 (G20) durante la crisis del Atlántico Norte de 2008-2009³. En este ensayo se analizan el debate y las decisiones adoptadas en materia de cooperación financiera internacional y en qué medida benefician a América Latina ${ }^{4}$. Está dividido en seis secciones, la primera de las cuales es esta introducción. Como marco de referencia, en la segunda sección se hacen algunas consideraciones sobre el contexto mundial y latinoamericano. En la tercera se presenta un análisis general de la cooperación financiera internacional, y en la cuarta y quinta se analizan con detalle la cooperación monetaria y el apoyo de los bancos multilaterales de desarrollo y su impacto en América Latina. En la última sección se presentan unas breves conclusiones.

Cabe señalar que las contribuciones de los académicos a los debates en curso han sido numerosas ${ }^{5}$. Aquí no haré justicia a ellas, aunque me referiré a las propuestas que han formulado algunos autores. El análisis estará basado mucho más en los debates internacionales y las decisiones que han adoptado los principales organismos multilaterales para abordar los problemas financieros que enfrentan las economías emergentes.

2 Véase el seguimiento que hace el BID sobre la expansión de la pandemia en la región en BID (2020).

3 Prefiero este término al más usado de "crisis financiera global" porque, aunque sus efectos fueron globales, la crisis se concentró en los Estados Unidos y Europa Occidental.

4 En mi análisis de América Latina no incluyo a Cuba, que no es objeto de la cooperación financiera internacional que analizo, ni a Haití, que sí lo es, pero a través de mecanismos especiales para países de muy bajos ingresos, a los cuales me refiero solo en forma marginal. Por su parte, la República Bolivariana de Venezuela enfrenta problemas particulares con algunas de las instituciones financieras internacionales que se mencionan a lo largo del ensayo.

5 Véase, entre muchos otros, Baldwin y Weder di Mauro (2020), Levy (2020), Stiglitz y otros (2020), y mis contribuciones con otros colegas en Gallagher, Ocampo y Volz (2020), Gallagher y otros (2020), y Griffith-Jones, Marodon y Ocampo (2020). 


\section{El contexto mundial y latinoamericano}

En el reciente informe del FMl sobre perspectivas de la economía mundial (FMI, 2020a) se estima una disminución del producto interno bruto (PIB) mundial a tasas de cambio de mercado del 4,2\% en $2020^{6}$. Este es el resultado de caídas de entre el $5 \%$ y el $7 \%$ de las principales economías desarrolladas y del $5 \%$ o más de las economías emergentes y en desarrollo, siendo América Latina, entre estas últimas, la región con peor desempeño. La profunda recesión refleja los efectos devastadores del confinamiento sobre la actividad económica: contracciones trimestrales que ya fueron marcadas en el primer trimestre ${ }^{7}$ y que pueden ser de dos dígitos en muchas economías en el segundo trimestre. El pronóstico básico del FMl supone que esos efectos se irán disipando gradualmente, pero claramente existe la incertidumbre de si existirán recursos médicos que impidan nuevos rebrotes.

Esta crisis, que tiene un alcance realmente global, será ciertamente más fuerte que la que experimentó la economía mundial durante la crisis del Atlántico Norte (-2,0\% en 2009, según el FMI, a tasas de cambio de mercado), que no tuvo lugar en un amplio grupo de economías emergentes y en desarrollo. Si se compara con la Gran Depresión, la velocidad de la contracción ha sido más acelerada, pero puede ser menos profunda y, sobre todo, menos prolongada ${ }^{8}$. La proyección básica del FMl es de un crecimiento del 5,4\% en 2021, que compensaría con creces la recesión de 2020, aunque no en todos los países. Sin embargo, si contener la pandemia toma más tiempo de lo esperado, el FMI estima que habría una caída del 3\% adicional en 2020, y si se combina con un rebrote en 2021, la actividad se ubicaría un $8 \%$ por debajo de lo proyectado para el próximo año ${ }^{9}$.

Ante ello, los países desarrollados han venido adoptando medidas agresivas en materia de aumento del gasto público, disminución o rezago del pago de impuestos, y provisión de liquidez, líneas de financiamiento y garantías para el sector empresarial. Tanto en materia fiscal como monetaria, el FMI estima que los paquetes de medidas son más grandes que los que se adoptaron para hacer frente a la crisis del Atlántico Norte, aunque con diferencias entre los países (FMI, 2020b y 2020c). En cambio, las medidas de reactivación de China han sido menos pronunciadas que las adoptadas entonces, debido al menor margen fiscal con el que cuenta hoy este país asiático, un tema que afecta en forma más generalizada a muchas economías emergentes y en desarrollo.

Inicialmente, los efectos sobre los mercados financieros fueron devastadores. Sin embargo, la magnitud de la intervención de los bancos centrales permitió que las caídas de dichos mercados fueran menos pronunciadas que en 2008-2009, e incluso generó una recuperación parcial de los mercados financieros desde fines de marzo (FMl, 2020b). Uno de los efectos más destacados fue la peor salida de la historia de capitales de cartera desde economías emergentes, que superó los 100.000 millones de dólares (Brooks y Fortun, 2020; FMl, 2020b). Sin embargo, como veremos en la cuarta sección, aunque los márgenes de riesgo para estas economías han permanecido altos, los rendimientos de los bonos y el costo de nuevo financiamiento se han reducido hasta niveles relativamente moderados gracias a la reducción de las tasas de interés de referencia (las de los bonos del Tesoro de los Estados Unidos), y varios países han comenzado a emitir bonos en los mercados internacionales desde mediados de abril, en forma mucha más rápida que en las crisis del pasado.

6 La estimación que ha hecho pública el FMl es del -3,0\%, a precios de paridad, pero este dato no es comparable con las estimaciones a tasas de cambio de mercado de las Naciones Unidas, el Banco Mundial y la mayor parte de los analistas privados.

7 Una contracción del 6,8\% en el caso de China, el país que fue afectado en forma más temprana, del 4,8\% en los Estados Unidos y del $3,8 \%$ en la zona del euro.

8 Esto es cierto en particular en el caso de los Estados Unidos, que durante la Gran Depresión experimentó una contracción durante tres años consecutivos, con una disminución acumulada del 27\% de acuerdo con las cifras históricas de Maddison (2010) y solo regresó a los niveles de 1929 una década después.

9 Estas estimaciones se hacen a precios de paridad. 
Otro efecto de la crisis ha sido una grave contracción del comercio internacional: se ha profundizado la caída en los volúmenes y valor del comercio que se había iniciado a fines de $2019^{10}$. La Organización Mundial del Comercio (OMC, 2020) estima que la caída del volumen de comercio se ubicará entre el $13 \%$ en el escenario base y el $32 \%$ en el más pesimista. La crisis puede generar, de hecho, la destrucción o contracción de numerosas cadenas internacionales de valor. Por este motivo, la recuperación del comercio puede ser mucho más lenta que la de 2010, que compensó con creces la caída de 2009. Por su parte, en materia de productos básicos, la crisis ha generado una fuerte reducción de los precios del petróleo y otros productos energéticos, una diminución menos pronunciada de los precios de los metales básicos y una tendencia diversa en el caso de los productos agrícolas ${ }^{11}$.

América Latina enfrenta estas graves perturbaciones externas después de un lustro (2015-2019) de crecimiento anémico, el peor desde la Segunda Guerra Mundial, y peor, de hecho, que los cinco años de menor crecimiento durante la crisis de la deuda y a los que sucedieron a la crisis asiática de 1997 (véase el gráfico 1). En los últimos cinco años, el crecimiento del PIB regional alcanzó apenas el 0,2\% (0,9\% si se excluye a la República Bolivariana de Venezuela). Este pobre desempeño refleja no solo problemas económicos, sino también crisis y transiciones políticas complejas en varios países.

Gráfico 1

América Latina: crecimiento del PIB, 1950-2020ª

(En porcentajes)

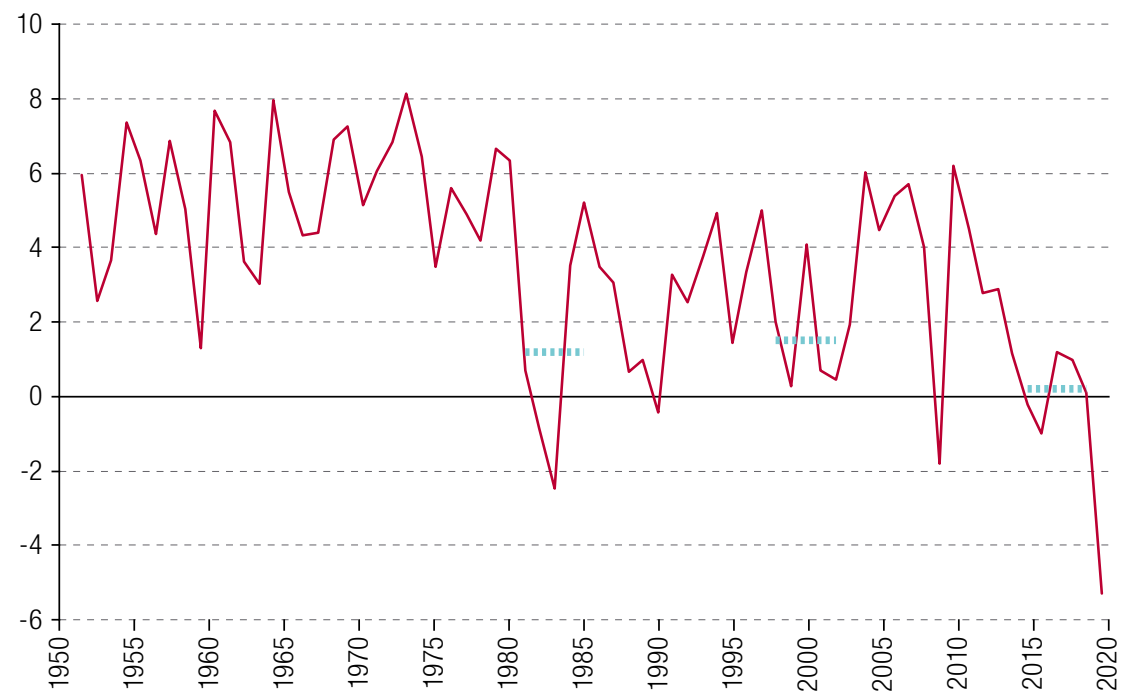

Fuente: Elaboración propia, sobre la base de datos de la Comisión Económica para América Latina y el Caribe (CEPAL).

Nota: Las líneas punteadas horizontales se refieren al promedio anual de crecimiento durante los tres quinquenios de bajo crecimiento, específicamente 1980-1985, 1997-2002 y 2015-2019.

a Las cifras de 2020 son estimaciones.

Cabe resaltar, sin embargo, que los problemas económicos de América Latina empezaron mucho antes de la ola reciente de inestabilidad económica y política. El crecimiento económico de la región durante las tres últimas décadas (1990-2019) ha sido de solo el 2,7\% anual, la mitad del alcanzado en los 30 años que precedieron a la década perdida (5,5\% de crecimiento anual promedio en 1950-1980). Casi todas las economías de la región han crecido menos que entonces (las excepciones son: Chile,

10 Véase al respecto las estadísticas que publica mensualmente el Netherlands Bureau of Economic Policy Analysis (CPB). Estas cifras indican que el crecimiento del promedio móvil de 12 meses del volumen de exportaciones mundiales era negativo desde octubre de 2019 y en valores desde agosto de ese año (CPB, s/f).

${ }^{11}$ Los datos del FMI (2020f) sobre precios de productos básicos indican que el de los productos energéticos había disminuido un 59,5\% en relación con el promedio de 2019 (el petróleo un 65,0\%), el de los metales básicos, un 14,7\%, y el de los productos agrícolas que se usan como insumos industriales, un 9,4\%, pero el de los alimentos y bebidas solo un 5,5\%. Las proyecciones del Banco Mundial (2020a) para el conjunto del año siguen este patrón. 
el Estado Plurinacional de Bolivia y el Uruguay); la caída ha sido particularmente drástica en los casos de Brasil, México y la República Bolivariana de Venezuela. Esto indica que, más allá de la crisis actual, hay que examinar en profundidad los patrones de desarrollo de la región.

Todos los organismos multilaterales (Banco Mundial, 2020b; CEPAL, 2020a y 2020b; FMI, 2020a; Nuguer y Powell, 2020) proyectan una recesión marcada de América Latina en 2020, con una recuperación solo parcial en 2021. Como se indica en el cuadro 1, los organismos estiman una caída en torno al 5\% para la región en su conjunto, que será particularmente marcada en la Argentina, el Brasil, el Ecuador, México y la República Bolivariana de Venezuela. Entre los países de mayor tamaño, Chile y el Perú se verían menos afectados, y Colombia sería el que tendría el mejor desempeño comparativamente, de acuerdo con estas proyecciones ${ }^{12}$. En general, los países más pequeños, con excepción del Ecuador, tendrían un mejor desempeño. Para la región en su conjunto, la recesión de 2020 sería la peor desde la Segunda Guerra Mundial (de hecho, mucho peor que la de 1983, el peor año de la crisis de la deuda) y una de las peores de la historia ${ }^{13}$.

\section{Cuadro 1}

América Latina y el Caribe: crecimiento económico 2019 y proyecciones 2020-2021

(En porcentajes de tasas de crecimiento)

\begin{tabular}{lccccc}
\hline & \multicolumn{2}{c}{ CEPAL } & & FMI & Banco Mundial \\
\cline { 2 - 3 } \cline { 5 - 6 } & 2019 & 2020 & & 2020 & 2020 \\
\hline Argentina & $-2,2$ & $-6,5$ & & $-5,7$ & $-5,2$ \\
\hline Brasil & 1,1 & $-5,2$ & & $-5,3$ & $-5,0$ \\
\hline Colombia & 3,3 & $-2,6$ & & $-2,4$ & $-2,0$ \\
\hline Chile & 1,1 & $-4,0$ & & $-4,5$ & $-3,0$ \\
\hline Ecuador & 0,1 & $-6,5$ & & $-6,3$ & $-6,0$ \\
\hline México & $-0,1$ & $-6,5$ & & $-6,6$ & $-6,0$ \\
\hline Perú & 2,2 & $-4,0$ & & $-4,5$ & $-4,7$ \\
\hline Venezuela (República Bolivariana de) & $-25,5$ & $-18,0$ & & $-15,0$ & n.d. \\
\hline América Latina y el Caribe & & & & $-5,2$ & $-4,6$ \\
\hline 2020 & 0,1 & $-5,3$ & & 3,4 & 2,6 \\
\hline 2021 & & & &
\end{tabular}

Fuente: Elaboración propia, sobre la base de Comisión Económica para América Latina y el Caribe (CEPAL), "Dimensionar los efectos del COVID-19 para pensar en la reactivación", Informe Especial COVID-19, № 2, Santiago, 21 de abril de 2020: Fondo Monetario Internacional (FMI), World Economic Outlook: The Great Lockdown, Washington, D.C., abril de 2020; y Banco Mundial, "La economía en los tiempos del COVID-19", Informe Semestral de la Región América Latina y el Caribe: la economía en los tiempos del COVID-19, Washington, D.C., abril de 2020.

Los organismos reconocen el deficiente desempeño económico de la región en el último lustro, así como los choques económicos que enfrenta como resultado de la pandemia de COVID-19. A las perturbaciones financieras, la contracción del comercio internacional y la disminución de los precios de los productos básicos ya mencionados se pueden añadir la intensa caída que experimentará el comercio intrarregional y el colapso del turismo. Se agregan, además, las reducciones de las remesas, tanto desde el exterior (especialmente desde los Estados Unidos y España), como intrarregionales, que en su conjunto disminuirán un 19\% en 2020 de acuerdo con las previsiones del Banco Mundial (2020c).

En materia de política económica, la gran restricción es el margen fiscal con el que cuentan los países de la región, mucho más limitado del que tuvieron para enfrentar la crisis del Atlántico Norte,

12 Con respecto a Colombia, véanse las proyecciones de la Fundación para la Educación Superior y el Desarrollo (FEDESARROLLO) (2020), que en un escenario más optimista prevé una caída del 2,7\% pero contempla también dos alternativas con contracciones del PIB del 5,0\% y del 7,9\%, que parecen más probables. La situación es aún más compleja para el Perú, de acuerdo con los datos preliminares para los primeros meses de 2020.

${ }^{13}$ De acuerdo con los datos de las diez economías para las cuales existe información desde 1900 (véase el cuadro 1 del Apéndice Estadístico de Bértola y Ocampo (2013)), los únicos años peores serían 1914 y 1930. Sin embargo, si la crisis actual se profundiza, como es muy probable que ocurra, sería la peor de la historia. 
un tema que han destacado varios analistas del Banco Interamericano de Desarrollo (BID). Izquierdo y Ardanaz (2020) resaltan que el déficit promedio de los países de la región fue del 3\% del PIB en 2019, en comparación con el $0,4 \%$ en 2008 , en tanto que la deuda pública promedio fue del $62 \%$ del PIB en 2019, en comparación con el 40\% en 2008.

La respuesta de los países de la región ha estado acorde con las tendencias internacionales. Los bancos centrales han provisto liquidez (con restricciones obvias en los países con economías dolarizadas). Los gobiernos han adoptado programas fiscales, especialmente de apoyo al sector de la salud y a los hogares pobres y vulnerables, así como medidas de reducción o postergación del pago de algunos impuestos, pero el tamaño de los paquetes de medidas es muy variable. Según las estimaciones del BID, los paquetes de mayor tamaño como porcentaje del PIB son los del Brasil, Chile, El Salvador y el Perú (Pineda, Pessino y Rasteletti, 2020). Algunos países han lanzado líneas de crédito o garantías crediticias en escala importante. En ese sentido, los casos más destacados son los de Chile, Colombia, el Perú y el Uruguay. Pese a lo anterior, la magnitud de los apoyos en la mayor parte de los países de la región es modesta comparada con la de los países desarrollados.

Los efectos sociales serán notorios, como ha resaltado la CEPAL (2020b). Se dan, además, en un contexto de deterioro de las condiciones sociales que ha tenido lugar desde 2014 como resultado del deficiente desempeño económico. Las insuficientes inversiones en salud se reflejan en sistemas de salud débiles y fragmentados que no garantizan el acceso universal en muchos países. La suspensión de las clases presenciales ha interrumpido los programas de alimentación escolar, que varios países han buscado continuar de distintas maneras, incluso con subsidios en dinero. Debido a la gran brecha digital, los estudiantes de escasos recursos no pueden beneficiarse de la educación virtual. Por su parte, la informalidad laboral implica que una alta proporción de hogares se queden sin ingresos, sin que las ayudas que proporcionan las transferencias condicionadas necesariamente les lleguen, especialmente a aquellos que no son pobres, pero sí vulnerables. Muchas micro, pequeñas y medianas empresas (mipymes) pueden quebrar, lo que es muy preocupante, ya que generan una elevada proporción del empleo en la región. Como resultado de todo ello, la CEPAL (2020b) estima, en su escenario medio, que la pobreza aumentará del 30,3\% en 2019 al 34,7\% en 2020, lo que equivale a casi 29 millones más de personas en situación de pobreza.

\section{Una visión general sobre la cooperación financiera internacional durante la crisis}

En el debate internacional se ha resaltado que, si bien la pandemia ha afectado en forma temprana y dramática a Europa Occidental y los Estados Unidos y ha llegado con rezago a los países en desarrollo, estos últimos son económica y socialmente más vulnerables. Las razones son múltiples: el confinamiento es más costoso para la población de escasos recursos de los países en desarrollo, que vive en espacios pequeños y congestionados y, a veces, sin acceso a agua; los mecanismos de apoyo para los sectores pobres no existen o no llegan a la población deseada; los sistemas de salud son de deficiente calidad y no cubren a toda la población; y la informalidad laboral es cuantiosa e implica que el confinamiento deja sin ingresos a un conjunto amplio de trabajadores. A todo ello se agrega que los márgenes fiscales son más reducidos y el acceso de los gobiernos al crédito es más limitado. Por este motivo, existe un acuerdo en torno a la necesidad de adoptar políticas ambiciosas para apoyar a los países con economías emergentes y en desarrollo. Las necesidades financieras de estos países son inmensas: 2,5 billones de dólares, de acuerdo con las estimaciones tanto del FMI (2020b) como de la Conferencia de las Naciones Unidas sobre Comercio y Desarrollo (UNCTAD, 2020a).

Frente a estas vulnerabilidad y necesidades, la cooperación internacional acordada hasta ahora es muy limitada, tanto en términos de medidas adoptadas como de recursos a los cuales tendrán acceso las economías emergentes y en desarrollo. Esto es particularmente cierto en relación con los 
países de renta media, a los cuales pertenecen casi todos los países latinoamericanos. Como veremos, las medidas han sido algo más relevantes - aunque de todas maneras insuficientes - para los países de más bajos ingresos, y es mucho más probable que estas se profundicen.

La debilidad de la cooperación multilateral fue particularmente evidente en las reuniones del G20 y las instituciones de Bretton Woods que tuvieron lugar en abril. De hecho, estas reuniones serán recordadas, no solo por haber sido las primeras de la historia que se realizaron en forma virtual, sino también por las limitadas decisiones internacionales adoptadas frente a la magnitud de la crisis en curso.

Ha habido, por supuesto, expresiones de solidaridad internacional. Los Líderes del G20 se comprometieron a fines de marzo a hacer lo que fuera necesario y a utilizar todas las herramientas de política disponibles para minimizar los daños económicos y sociales generados por la pandemia, restablecer el crecimiento mundial, mantener la estabilidad de los mercados y fortalecer la resiliencia (G20, 2020a). Los ministros de hacienda y los gobernadores de los bancos centrales de los países integrantes del G20 expresaron algo similar en su declaración durante las reuniones de las instituciones de Bretton Woods.

Sin embargo, las medidas multilaterales no han coincidido con estas promesas. De hecho, las acciones en marcha distan de lo establecido en el Plan Mundial de Recuperación y Reforma convenido por el G20 y adoptado por los Líderes del G20 en Londres el 2 de abril de 2009 para enfrentar la crisis de entonces (G20, 2009). Dicha declaración condujo a la reforma más importante de las líneas de crédito del FMl de su historia, a la mayor emisión de derechos especiales de giro (DEG) del FMl, a la capitalización y el aumento masivo de préstamos de los bancos multilaterales de desarrollo y a una ambiciosa reforma de la regulación financiera. Con rezago, condujo también al inicio de los esfuerzos por fortalecer la cooperación tributaria internacional, que se encargó a la Organización de Cooperación y Desarrollo Económicos (OCDE), a la adopción en 2012 de la llamada "visión institucional" del FMl sobre flujos de capital, y al aumento y la redistribución de las cuotas del FMI. Desafortunadamente, esta última tardó cinco años por la demora en la aprobación de los recursos correspondientes por parte del Congreso de los Estados Unidos ${ }^{14}$.

En comparación con estas acciones y con las necesidades de las economías emergentes y en desarrollo, los anuncios en las reuniones de las instituciones de Bretton Woods y las acciones paralelas impulsadas por el G20 han sido minúsculos. Esta limitada cooperación internacional contrasta con las ambiciosas políticas internas que han adoptado los países desarrollados. En el caso particular de los Estados Unidos, sus políticas internas han sido mucho más agresivas que las que adoptó frente a la crisis financiera de 2008-2009 y, a diferencia también con el liderazgo internacional que ejerció durante la crisis de 2008-2009, su apoyo a las acciones internacionales ha sido muy limitado durante la crisis actual. Los países europeos han adoptado también políticas contracíclicas pronunciadas, pero han estado más abiertos a la cooperación multilateral. El contraste entre las agresivas políticas económicas internas de los países desarrollados y la limitada cooperación internacional parece ser un rasgo principal de la crisis en curso.

\section{La cooperación monetaria internacional y sus efectos sobre América Latina}

La agenda monetaria internacional incluye seis áreas: i) la provisión de liquidez internacional; ii) la creación y ampliación de las líneas de crédito del FMI, iii) la garantía de que este organismo contará con recursos adecuados; iv) la posible coordinación de la regulación de los flujos de capital y de las decisiones de las agencias calificadoras de riesgo; v) las acciones orientadas a manejar el sobreendeudamiento de varias economías emergentes y en desarrollo, y vi) el uso activo y la expansión de los acuerdos monetarios regionales (Gallagher y otros, 2020).

\footnotetext{
14 Véase un análisis detallado de estos temas en Ocampo (2017).
} 
En materia de provisión de liquidez, la propuesta que ha recibido el apoyo más amplio ha sido la emisión de al menos 500.000 millones de DEG, lo que duplica la emisión que se hizo en $2009^{15}$. Para hacer un mejor uso de esta emisión, se podría crear un fondo especial para que los países que no utilicen los DEG recibidos los presten al FMI para financiar sus programas, o los utilicen para apoyar otros programas de desarrollo (capitalizar los bancos multilaterales o aumentar la asistencia oficial para el desarrollo). Sería conveniente que la distribución de los DEG se basara en criterios diferentes a los que se aplican para distribuir las cuotas ${ }^{16}$, pero esto requeriría un cambio en el Convenio Constitutivo del FMI.

Dada la participación de los países latinoamericanos en las cuotas del FMI, esta emisión implicaría un aumento de sus reservas internacionales de 37.740 millones de dólares, equivalente a algo menos del $5 \%$ de dichas reservas a fines de 2019 y a poco más del $40 \%$ del saldo neto de la cuenta de capitales y financiera de la región en dicho año ${ }^{17}$. La distribución por país sería la que se muestra en el cuadro 2; como proporción del PIB alcanzarían el 0,7\% en promedio, oscilando entre el 0,6\% y 0,8\% para la mayoría de los países, pero llegarían a un monto superior para aquellos en los cuales el PIB en dólares se ha reducido sustancialmente en años recientes.

Cuadro 2

Cuotas de países latinoamericanos en el Fondo Monetario Internacional (FMI)

\begin{tabular}{lccccc}
\hline & \multicolumn{3}{c}{ Cuota en el FMI } & & \multicolumn{2}{c}{$\begin{array}{c}\text { Efecto de una emisión de } \\
\text { 500.000 millones de dólares }\end{array}$} \\
\cline { 2 - 3 } \cline { 5 - 6 } & Millones de DEG & $\begin{array}{c}\text { Millones de } \\
\text { dólares }\end{array}$ & $\begin{array}{c}\text { Porcentaje } \\
\text { del total }\end{array}$ & $\begin{array}{c}\text { Millones de } \\
\text { dólares }\end{array}$ & Porcentaje del PIB \\
\hline Brasil & 11042 & 15120 & 2,31 & 11574 & 0,62 \\
\hline México & 8913 & 12204 & 1,87 & 9342 & 0,77 \\
\hline Venezuela (República Bolivariana de) & 3723 & 5097 & 0,78 & 3902 & 2,52 \\
\hline Argentina & 3187 & 4364 & 0,67 & 3341 & 0,65 \\
\hline Colombia & 2045 & 2799 & 0,43 & 2143 & 0,65 \\
\hline Chile & 1744 & 2388 & 0,37 & 1828 & 0,62 \\
\hline Perú & 1335 & 1827 & 0,28 & 1399 & 0,63 \\
\hline Ecuador & 698 & 955 & 0,15 & 731 & 0,68 \\
\hline República Dominicana & 477 & 654 & 0,10 & 500 & 0,59 \\
\hline Uruguay & 429 & 588 & 0,09 & 450 & 0,76 \\
\hline Guatemala & 429 & 587 & 0,09 & 449 & 0,62 \\
\hline Panamá & 377 & 516 & 0,08 & 395 & 0,61 \\
\hline Costa Rica & 369 & 506 & 0,08 & 387 & 0,65 \\
\hline El Salvador & 287 & 393 & 0,06 & 301 & 1,16 \\
\hline Nicaragua & 260 & 356 & 0,05 & 273 & 2,09 \\
\hline Honduras & 250 & 342 & 0,05 & 262 & 1,10 \\
\hline Bolivia (Estado Plurinacional de) & 240 & 329 & 0,05 & 252 & 0,63 \\
\hline Paraguay & 201 & 276 & 0,04 & 211 & 0,53 \\
\hline Total de América Latina & 36006 & 49302 & 7,55 & 37740 & 0,72 \\
\hline
\end{tabular}

Fuente: Elaboración propia, sobre la base de datos del Fondo Monetario Internacional (FMI) y la Comisión Económica para América Latina y el Caribe (CEPAL).

Nota: Los valores en DEG están convertidos a dólares con la tasa de cambio del 1 de mayo de 2020. Las estimaciones como porcentaje del PIB se refieren a 2018, con base en las estimaciones de la CEPAL del PIB en ese año.

Hay propuestas más ambiciosas, como la de emitir un billón de dólares en DEG (véase, por ejemplo, Cardoso y otros, 2020). Aunque sería conveniente, esto exigiría una aprobación explícita y no una mera comunicación al Congreso de los Estados Unidos, necesaria cuando los DEG que va

\footnotetext{
15 Véase una versión temprana de esta propuesta en Gallagher, Ocampo y Volz (2020). Véase también Collins y Truman (2020).

${ }^{16}$ Como refleja un largo debate histórico, los criterios alternativos podrían ser el nivel de desarrollo y la demanda de reservas internacionales de distintas economías (Ocampo, 2017, cap. II).

17 Los datos de referencia se toman de CEPAL (2019).
} 
a recibir este país superan su cuota en el FMI. Sin duda, ello retrasaría la emisión e implicaría que la emisión máxima que podría hacerse sin tener que contar con la aprobación de dicho órgano legislativo es igual al total de cuotas en el FMl, en torno a los 650.000 millones.

Aunque la propuesta de una cuantiosa emisión de DEG tenía un amplio respaldo entre los miembros del FMl y la opinión pública, fue vetada por los Estados Unidos durante las reuniones de las instituciones de Bretton Woods, con el argumento de que cerca del 70\% de los recursos irían a países del G20, la mayoría de los cuales no los necesitan (Mnuchin, 2020). Sorprendentemente, la India apoyó esta posición. Aunque es cierto que poco menos de dos quintas partes de las emisiones de DEG favorecen a las economías emergentes y en desarrollo, también lo es que esta es la única participación que tienen en la creación de dinero internacional (señoraje). De hecho, los beneficios de la emisión de DEG serían importantes para muchos países de bajos ingresos (Collins y Truman, 2020).

Para contribuir a la creación de liquidez internacional, la Reserva Federal de los Estados Unidos relanzó sus líneas de canje de monedas (currency swaps) con otros bancos centrales, siguiendo una práctica que ya había puesto en marcha durante la crisis del Atlántico Norte. Sin embargo, a este mecanismo solo tienen acceso cuatro economías emergentes: Brasil, México, la República de Corea y Singapur. Un mecanismo nuevo fue la creación de un instrumento de repos, que le permite a la Reserva Federal comprar los bonos del Tesoro que los países deseen venderle, un apoyo que beneficia a países con cantidades importantes de reservas internacionales.

En términos de creación y ampliación de líneas de crédito, la reforma más importante ha sido la duplicación de las líneas de crédito de emergencia del FMI, como el Instrumento de Financiamiento Rápido (IFR), disponible para los países de renta media ${ }^{18}$. En el contexto de una simplificación y agilización de procedimientos y la ausencia de condicionalidad ex ante, esta decisión está dando lugar a la rápida aprobación de una multiplicidad de créditos para un conjunto amplio de países ${ }^{19}$. Al 1 de abril, siete países latinoamericanos usaron esta línea, obteniendo en conjunto un monto ligeramente superior a 3.300 millones de dólares (véase el cuadro 3); no hubo ninguno adicional en en lo que restó de mayo.

\section{Cuadro 3}

Préstamos aprobados a países latinoamericanos por el Instrumento de Financiamiento Rápido, 2020

\begin{tabular}{lccc}
\hline País & Millones de DEG & Fecha de aprobación & Millones de dólares \\
\hline Bolivia (Estado Plurinacional de) & 240,1 & 17 de abril & 328,8 \\
\hline Costa Rica & 369,4 & 29 de abril & 505,8 \\
\hline Ecuador & 469,7 & 1 de mayo & 643,2 \\
\hline El Salvador & 287,2 & 14 de abril & 393,3 \\
\hline Panamá & 376,8 & 15 de abril & 515,9 \\
\hline Paraguay & 201,4 & 21 de abril & 275,8 \\
\hline República Dominicana & 477,4 & 29 de abril & 653,7 \\
\hline Total & 2422,0 & & 3316,4 \\
\hline
\end{tabular}

Fuente: Elaboración propia, sobre la base de datos del Fondo Monetario Internacional (FMI).

Nota: Los valores en derechos especiales de giro (DEG) se convirtieron a dólares con la tasa de cambio del 1 de mayo de 2020.

A esos países se agregan los que se benefician de otras facilidades crediticias, varios de ellos desde antes de la crisis actual: las líneas de crédito flexible preexistentes de México y Colombia (esta última renovada el 1 de mayo) y las nuevas otorgadas al Perú y Chile a fines de mayo ${ }^{20}$, los créditos

\footnotetext{
18 Sobre estas y otras reformas introducidas por el FMI, véase FMI (2020e).

${ }^{19}$ Existe también la posibilidad de que sean adicionales al uso de otros instrumentos del Fondo, pero en este caso los créditos de emergencia se dan generalmente por menos del monto de la cuota del país. Esto aconteció con Ecuador el 1 de mayo, cuando la línea de financiamiento rápido se aprobó por el 67,3\% de su cuota.

${ }^{20}$ El monto de las líneas de crédito flexible aprobadas para Chile y el Perú equivalen a 10 y 6 veces sus cuotas, respectivamente, muy superiores a las de México y Colombia, que equivalen a 5 y 3,8 veces sus cuotas, respectivamente.
} 
stand-by de la Argentina y Honduras, este último incrementado el 1 de junio, y el servicio ampliado al cual accedió el Ecuador, pero que fue suspendido el 1 de mayo ${ }^{21}$ (véase el cuadro 4). De esta manera, 13 países de la región tienen algún apoyo del FMI. Dado que las líneas de crédito flexible operan como una especie de "seguro" para los países, no han sido desembolsadas hasta ahora; los desembolsos de las otras líneas suman poco más de $\mathbf{4 5 . 7 0 0 ~ m i l l o n e s ~ d e ~ d o ́ l a r e s ~ ( l a ~ m a y o r ~ p a r t e ~ c o r r e s p o n d e ~ a ~}$ la Argentina). La excepción en términos de acceso es la República Bolivariana de Venezuela, cuya solicitud de crédito por 5.000 millones de dólares fue rechazada en marzo por el FMI con el argumento de que no existe claridad entre sus Estados miembros sobre quién es el presidente legítimo del país.

\section{Cuadro 4}

Préstamos regulares aprobados a países latinoamericanos por el Fondo Monetario Internacional (FMI) vigentes en mayo de 2020

\begin{tabular}{|c|c|c|c|c|c|}
\hline & \multirow{2}{*}{ Fecha de aprobación } & \multirow{2}{*}{ Vencimiento } & \multicolumn{2}{|c|}{ Monto del préstamo (DEG) } & \multirow{2}{*}{$\begin{array}{c}\text { Desembolsado } \\
\text { Millones de dólares }\end{array}$} \\
\hline & & & Millones de DEG & Millones de dólares & \\
\hline \multicolumn{6}{|c|}{ A. Línea de crédito flexible } \\
\hline México & 22 de noviembre de 2019 & 21 de noviembre de 2021 & 44563,5 & 61019,9 & 0,0 \\
\hline Colombia & 1 de mayo de 2020 & 30 de abril de 2022 & 7849,6 & 10748,3 & 0,0 \\
\hline Perú & 28 de mayo de 2020 & 27 de mayo de 2022 & 8007,0 & 10963,8 & 0,0 \\
\hline Chile & 29 de mayo de 2020 & 28 de mayo de 2022 & 17443,0 & 23884,4 & 0,0 \\
\hline \multicolumn{6}{|c|}{ B. Acuerdos de derechos de giro (stand-by) } \\
\hline Argentina & 20 de junio de 2018 & 19 de junio de 2021 & 40714,0 & 55748,9 & 43698,8 \\
\hline Honduras $^{\mathrm{a}}$ & 15 de julio de 2019 & J14 de julio de 2021 & 387,2 & 530,2 & 376,3 \\
\hline \multicolumn{6}{|c|}{ C. Servicio ampliado } \\
\hline Ecuador & 11 de marzo de 2019 & 10 de marzo de 2022 & 3035,0 & 4155,8 & 1653,9 \\
\hline Total & & & 121999,3 & 167051,2 & 45729,0 \\
\hline
\end{tabular}

Fuente: Elaboración propia, sobre la base de datos de Fondo Monetario Internacional (FMI).

Nota: Los valores en derechos especiales de giro (DEG) se convirtieron a dólares con la tasa de cambio del 1 de mayo de 2020. a Incluye los recursos aprobados del Servicio de Crédito Stand-By (SCS) y el incremento aprobado el 1 de junio de 2020 ; se incluye también como desembolsado el monto autorizado en esta última fecha.

Otra de las recomendaciones que ha estado en el debate es la creación de una línea de canje (swap) del FMl. Esta recomendación fue hecha por el equipo técnico del FMl hace dos años (FMl, 2017b), pero fue rechazada por el Directorio. El Grupo de Personas Eminentes del G20 sobre la Gobernanza Financiera Mundial hizo posteriormente una recomendación similar (Grupo de Personas Eminentes del G20 sobre la Gobernanza Financiera Mundial, 2018). Puede decirse que la línea de liquidez de corto plazo creada por el FMl en abril responde a esta demanda, pero es una respuesta muy parcial. Operará como una línea de crédito rotatoria hasta por el $145 \%$ de la cuota del país y sin condicionalidad ex ante, pero a ella solo tendrán acceso los países miembros "con políticas y fundamentos muy fuertes", como acontece con la línea de crédito flexible. Sin embargo, su atractivo se limita porque sus recursos son muy inferiores a los de esta última y no puede ser combinada con otros créditos del Fondo. Por lo tanto, es muy probable que no sea utilizada.

Para poder financiar la mayor demanda de créditos, el FMI necesita ampliar los recursos con los que cuenta hasta una suma que la Directora Gerente ha estimado en un billón de dólares. En tal sentido, el año pasado se adoptó una decisión desafortunada al postergar el aumento de cuotas hasta 2023. Es lamentable que el G20 no haya decidido acelerar este proceso, dado el amplio reconocimiento de estos países de que este debe ser el principal recurso de la institución. Los fondos adicionales se obtendrán de la duplicación de los Nuevos Acuerdos para la Obtención de Préstamos (NAP), aprobada en enero de 2020 por hasta cerca de 500.000 millones de dólares, y de los créditos bilaterales que otorgan varios países. La principal contribución de los Estados Unidos será su aporte a los NAP.

Una cuarta línea de acción que ha sido propuesta por varios analistas es la posible coordinación de la regulación de los flujos de capital, tratando de frenar en particular la fuga de capitales de cartera

\footnotetext{
${ }^{21}$ En esa fecha se le dio acceso a la línea de emergencia. El Ecuador buscará otro crédito de largo plazo del FMl.
} 
desde las economías emergentes. Esta acción estaría acorde con la "visión institucional" sobre flujos de capital aprobada por el FMI en 2012 (FMl, 2012). De manera similar, se ha propuesto que las agencias evaluadoras de riesgo suspendan sus rebajas de calificaciones (o de perspectivas dentro de un grado de calificación) durante la crisis, ya que estas alimentan la fuga de capitales ${ }^{22}$. México y Colombia ya han sido afectados por decisiones de este tipo, aunque han mantenido su grado de inversión. Sobre estos temas no se ha pronunciado ni el G20 ni el FMl.

El quinto tema, el alivio de la deuda, ha sido objeto de una amplia gama de propuestas, tanto institucionales (Naciones Unidas, 2020; UNCTAD, 2020b) como de analistas (en particular, Bolton y otros, 2020; Brown y Summers, 2020; Reinhart y Rogoff, 2020). Este es un campo donde ya se han adoptado medidas parciales en relación con los países de bajos ingresos, pero no con los de renta media.

El FMl determinó que 25 de sus miembros más vulnerables (a los cuales se pueden adicionar otros cuatro en el futuro cercano) estarán exentos de amortizaciones e intereses de sus deudas con el organismo durante un período de seis meses, usando recursos del Fondo Fiduciario para Alivio y Contención de Catástrofes (FFACC). A su vez, el G20 ofreció una suspensión del servicio de la deuda de los países que reciben apoyo de la Asociación Internacional de Fomento (AIF) durante el resto de 2020, una medida que, de acuerdo con Brown y Summers (2020), debería extenderse a todo 2021. La decisión correspondiente ya ha sido adoptada por el Club de París. No es claro, sin embargo, que los acreedores privados la adopten, como ha solicitado el G20. Este programa no cancela la deuda, que seguirá pendiente y seguirá devengando intereses.

En caso de los países de renta media, hay casos críticos que requieren una restructuración de la deuda. Los casos más importantes en América Latina son la Argentina y el Ecuador. Aunque hay propuestas de suspensión relativamente generalizada del servicio de la deuda de las economías emergentes y en desarrollo (véanse especialmente UNCTAD (2020a y 2020b) y Reinhart y Rogoff (2020)), otras propuestas se orientan a sugerir mecanismos voluntarios.

La propuesta más interesante es la de Bolton y otros (2020) que sugiere crear un servicio de crédito financiero (central credit facility) central en el Banco Mundial o en los bancos regionales de desarrollo al cual acudirían en forma voluntaria los países, y que facilitaría un aplazamiento de las amortizaciones y el uso de los intereses debidos para financiar la emergencia sanitaria. Las obligaciones de los países seguirían vigentes y, por lo tanto, el mecanismo propuesto actuaría como un sistema de refinanciación durante la emergencia. Se aplicaría a todas las deudas bilaterales y comerciales en igualdad de condiciones. Aparte de su carácter voluntario, estaría sujeto a la intermediación y el monitoreo estricto por parte del banco multilateral que lo gestione.

Cabe agregar que, más allá de las medidas de corto plazo, las Naciones Unidas y la UNCTAD han señalado que debe crearse un mecanismo institucional para la renegociación de las deudas soberanas, tema que ha estado sobre la mesa durante las dos últimas décadas, con avances que se limitan a la definición de principios y cláusulas que permiten la renegociación de cada país con sus acreedores, pero sin un marco institucional específico ${ }^{23}$.

Es importante resaltar que para América Latina no tiene sentido adoptar una regla uniforme en este campo. De hecho, como se observa en el gráfico 2, aunque los márgenes de riesgo de los bonos emitidos por las economías emergentes se elevaron, permanecieron por debajo de los alcanzados durante la crisis del Atlántico Norte y, especialmente, después de la moratoria rusa de agosto de 1998 (que, a su vez, sucedió a la crisis asiática de 1997). Lo que es más importante, con la fuerte caída del rendimiento que se usa como referencia para calcular dichos márgenes (los del Tesoro de los Estados Unidos a diez años), los rendimientos de los bonos de las economías emergentes han permanecido muy por debajo de los alcanzados durante las dos crisis previas, e incluso de los que alcanzaron durante las perturbaciones de los mercados emergentes de bonos en 2018.

\footnotetext{
22 Véase sobre estos temas Gallagher y otros (2020).

${ }^{23}$ Véase un examen del debate correspondiente en Ocampo (2017), cap. V.
} 
Gráfico 2

Márgenes de riesgo y rendimiento de los bonos de economías emergentes (Índice EMBI de JPMorgan)

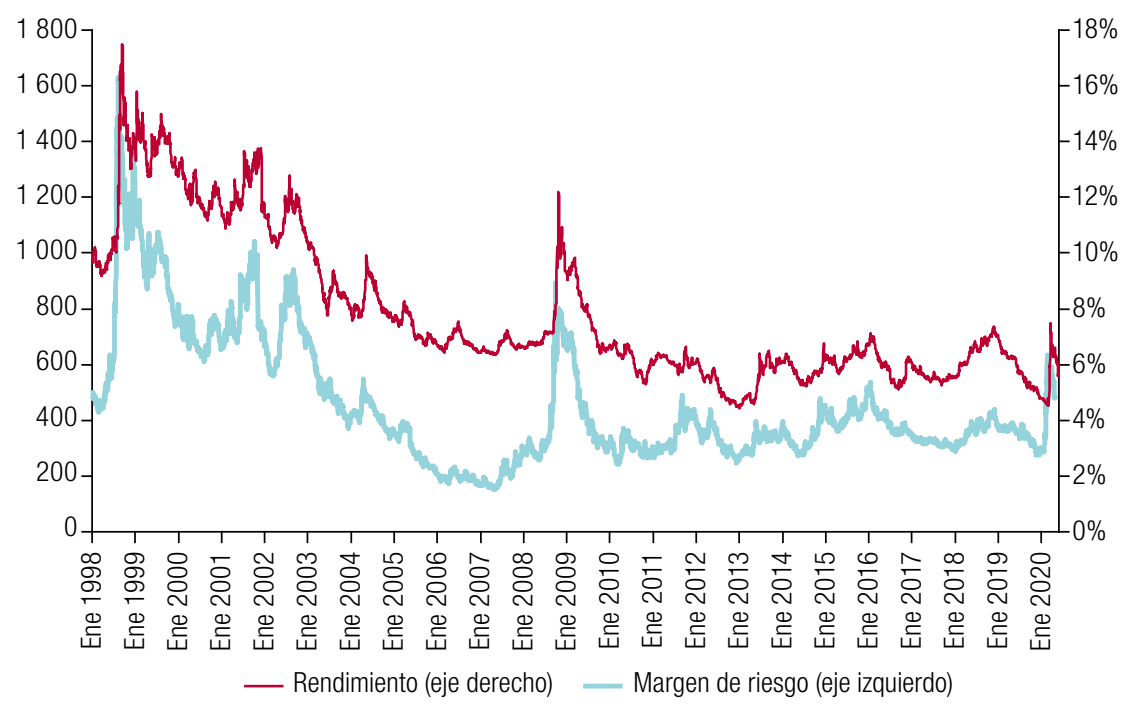

Fuente: Elaboración propia, sobre la base de datos de Bloomberg.

Más aún, los mercados de bonos para economías emergentes se han comenzado a abrir en forma mucho más rápida que después de la crisis del Atlántico Norte, cuando tardaron un poco más de 12 meses después del colapso del banco de inversión estadounidense Lehman Brothers. Esto indica que hay de nuevo una búsqueda de rendimientos (search for yield) de diversos fondos de inversiones de países desarrollados. Dos muestras de ello son la fuerte reducción de los márgenes de riesgo desde fines de marzo de 2020 (véase el gráfico 2) y la salida de capitales desde las economías emergentes, que alcanzó los 66.100 millones de dólares en marzo, se redujo a 11.300 millones de dólares en abril y a 10.000 millones de dólares en mayo, cuando el flujo de bonos en monedas duras se tornó positivo (JP Morgan, 2020).

Ocho países latinoamericanos ya se han visto favorecidos con emisiones de bonos: Panamá a fines de marzo, y desde mediados de abril el Perú, Guatemala, México, el Paraguay, Chile y Colombia, dos empresas públicas colombianas (Ecopetrol y el Grupo Energía Bogotá, ambas con participación privada minoritaria), dos chilenas (Corporación Nacional del Cobre de Chile (CODELCO) y el Metro de Santiago) y una brasileña (Petrobras). A ello se agregan las emisiones del Banco de Desarrollo de América Latina (CAF) y el Banco Centroamericano de Integración Económica (BCIE). A través de los mercados de bonos en monedas duras, se han conseguido 24.000 millones de dólares entre mediados de abril y el 1 de junio de 2020.

En esto contexto, no tiene sentido una solución uniforme para los problemas de la deuda de los países de la región y, en general, de los de renta media. Hay tres situaciones diferentes que habría que tratar por separado: i) países para los que habría que hacer una reestructuración profunda de sus deudas; ii) países que pudieran acudir voluntariamente a un mecanismo de suspensión del servicio de la deuda como el que proponen Bolton y otros (2020); y iii) países con acceso a nuevo financiamiento privado que mantendrían el servicio de la deuda y combinarían dicho financiamiento con créditos del FMl y de los bancos multilaterales de desarrollo.

Conviene resaltar, por último, el papel de los mecanismos monetarios regionales. Estos mecanismos se expandieron mucho desde la crisis del Atlántico Norte y disponen hoy de 585.400 millones de dólares, equivalentes aproximadamente a un $60 \%$ de los recursos con que cuenta el FMI, aunque concentrados en los fondos europeos y la Iniciativa de Chiang Mai de Asia Oriental (Gallagher y otros, 2020). La profundización de las relaciones entre el FMl y los acuerdos regionales para constituir una red 
de seguridad financiera mundial (global financial safety net) más densa debe ser objeto de un trabajo activo, como han reconocido tanto el FMI (2017a) como Cheng y otros (2018).

Esta colaboración debe partir de la complementariedad, pero también de la independencia de los organismos, el respeto a sus respectivos mandatos y estructuras de gobernabilidad, y no debe seguir principios jerárquicos de ningún tipo ${ }^{24}$. No es conveniente, además, que haya una relación formal con programas del FMI, que fueron objeto de muchas críticas durante la crisis de la eurozona y es una de las razones por las cuales no se han utilizado los recursos de la Iniciativa de Chiang Mai.

En el caso latinoamericano, se cuenta con el Fondo Latinoamericano de Reservas (FLAR), al cual pertenecen ocho países. Este organismo ha tenido una historia muy exitosa de apoyo a sus países miembros durante las diversas crisis que han enfrentado, que lo han utilizado a veces como sustituto y a veces como complemento de los recursos del FMI. En todo caso, dado los recursos limitados con los que cuenta el FLAR, el FMI resulta irremplazable para programas de gran tamaño. Como parte de las medidas de fortalecimiento de la red de seguridad financiera mundial, una tarea importante es ampliar su integración hasta alcanzar a la totalidad de los países latinoamericanos.

En el cuadro 5 se muestran los montos máximos que pueden recibir los países miembros en créditos del FLAR, tanto como cupo global como a través de sus líneas de crédito específicas (balanza de pagos, liquidez y contingencia). El monto total para los países miembros suma poco más de 6.500 millones de dólares, que están disponibles casi en su totalidad porque solo hay un crédito vigente, con el Ecuador (de balanza de pagos) por 205 millones de dólares, ya que los otros créditos, que habían tomado Costa Rica y la República Bolivariana de Venezuela, fueron cancelados a comienzos de 2020. Como el crédito de la República Bolivariana de Venezuela fue cancelado con cargo al capital pagado por ese país, el apoyo que el FLAR puede otorgarle ahora es reducido.

\section{Cuadro 5}

Capital y cupos máximos de créditos del Fondo Latinoamericano de Reservas (FLAR) (En millones de dólares)

\begin{tabular}{|c|c|c|c|c|c|c|}
\hline \multirow{2}{*}{ País } & \multirow{2}{*}{$\begin{array}{l}\text { Capital } \\
\text { suscrito }\end{array}$} & \multirow{2}{*}{$\begin{array}{l}\text { Capital } \\
\text { pagado }\end{array}$} & \multirow{2}{*}{$\begin{array}{l}\text { Cupo total } \\
\text { máximo }\end{array}$} & \multicolumn{3}{|c|}{$\begin{array}{l}\text { Cupos máximos de acceso por } \\
\text { modalidad de apoyo financiero }\end{array}$} \\
\hline & & & & $\begin{array}{c}\text { Apoyo a la } \\
\text { balanza de pagos }\end{array}$ & Liquidez & Contingencia \\
\hline Bolivia (Estado Plurinacional de) & 328,1 & 256,4 & 666,6 & 666,6 & 282,0 & 538,4 \\
\hline Colombia & 656,3 & 512,9 & 1282,3 & 1282,3 & 512,9 & 1025,9 \\
\hline Costa Rica & 656,3 & 513,1 & 1282,7 & 1282,7 & 513,1 & 1026,1 \\
\hline Ecuador & 328,1 & 256,5 & 666,8 & 666,8 & 282,1 & 538,6 \\
\hline Paraguay & 328,1 & 256,0 & 640,0 & 640,0 & 256,0 & 512,0 \\
\hline Perú & 656,3 & 512,9 & 1282,2 & 1282,2 & 512,9 & 1025,8 \\
\hline Uruguay & 328,1 & 257,0 & 642,4 & 642,4 & 257,0 & 513,9 \\
\hline $\begin{array}{l}\text { Venezuela (República } \\
\text { Bolivariana de) }\end{array}$ & 656,3 & 30,7 & 76,7 & 76,7 & 30,7 & 61,3 \\
\hline Total FLAR & 3937,5 & 2595,4 & 6539,7 & 6539,7 & 2646,6 & 5242,0 \\
\hline
\end{tabular}

Fuente: Elaboración propia, sobre la base de datos de Fondo Latinoamericano de Reservas (FLAR).

La gran ventaja del FLAR es que sus programas no tienen condicionalidad ex ante, aunque sí establecen la obligación del país de presentar un programa macroeconómico al organismo. Su principal desventaja es el tamaño de los recursos con los que cuenta, por lo que sus programas tendrán que ser casi seguramente complementarios con los del FMI. En ese caso, los países pueden utilizar el FLAR como complemento o como puente hacia un préstamo del FMl, aprovechando la mayor agilidad del primero para aprobar financiamiento. Una desventaja adicional durante la coyuntura actual es que los programas del FLAR son estrictamente de balanza de pagos y, por lo tanto, no pueden usarse para financiar a los gobiernos, en

\footnotetext{
${ }^{24}$ Esto significa que no se debe adoptar el principio de "agencia líder" que ha propuesto el FMI (2017a).
} 
un momento es que estas demandas son muy elevadas. Conviene, por lo tanto, aprobar una excepción temporal, que permita que los créditos de balanza de pagos se puedan utilizar también con fines fiscales.

\section{La cooperación de los bancos multilaterales de desarrollo}

Uno de los instrumentos financieros más importantes que tiene la comunidad internacional y un amplio conjunto de países, tanto desarrollados como de economías emergentes y en desarrollo, son los bancos de desarrollo. Estas instituciones tienen como objetivo fundamental apoyar las políticas de desarrollo de largo plazo - para el fomento a la innovación, el desarrollo de la infraestructura, la promoción de la equidad social y regional y la sostenibilidad ambiental -, pero su financiamiento también puede ser utilizado como instrumento contracíclico. Más aún, algunos proyectos asociados a estrategias de largo plazo pueden impulsarse durante las crisis para apoyar la reactivación.

La red de bancos de desarrollo incluye más de 400 instituciones a nivel mundial, con activos totales de más de 11 billones de dólares, y prestan unos 2 billones de dólares al año, de acuerdo con las estimaciones de la Agencia Francesa de Desarrollo (AFD). Incluyen al Grupo Banco Mundial, así como a varios bancos regionales (como el $\mathrm{BID}$ y la CAF) ${ }^{25}$, subregionales (el $\mathrm{BCIE}$ ) e interregionales (el Banco Islámico de Desarrollo), y un conjunto amplio de bancos nacionales de muy diverso tamaño. Una de sus grandes posibilidades es actuar como red de instituciones, de tal manera que los bancos multilaterales apoyen las acciones de los bancos nacionales. Si las entidades de esta red aumentaran su actividad un 20\%, podrían movilizar 400.000 millones de dólares adicionales en un año; con los recursos privados que apalancan, esta suma podría duplicarse (Griffith-Jones, Marodon y Ocampo, 2020).

Durante la crisis del Atlántico Norte, los bancos multilaterales de desarrollo cumplieron un papel contracíclico importante (Ocampo y otros, 2011), que fue reconocido en forma explícita por los propios bancos y por las autoridades económicas. Las lecciones del pasado indicaban que, además de provisión de liquidez en momentos de crisis por parte de instituciones monetarias internacionales, era igualmente importante que los bancos multilaterales proporcionen financiamiento oficial de largo plazo para apoyar el gasto público y la inversión pública y privada.

En conjunto, estas instituciones incrementaron un $71 \%$ sus compromisos de créditos para países con economías emergentes y en desarrollo entre 2008 y 2009; sus desembolsos crecieron un $45 \%$ en 2009 y siguieron haciéndolo en forma dinámica en 2010 (Ocampo y otros, 2011). Pese a las medidas adoptadas para acelerarlos, se produjo el rezago de los desembolsos. Curiosamente, la respuesta respecto de los países de renta media fue más intensa que respecto de los de renta baja, por lo cual los compromisos de crédito con estos últimos disminuyeron del 32\% en 2007 al 22\% en 2009.

La respuesta de los bancos se vio condicionada, en parte, por la limitación de su capital. Por este motivo, como se señaló en la tercera sección, en el Plan aprobado en su reunión de Londres de abril de 2009, el G20 acordó apoyar la capitalización de los bancos multilaterales de desarrollo. Las capitalizaciones del Banco Asiático de Desarrollo y el Banco Africano de Desarrollo fueron rápidas y cuantiosas: un 200\% de aumento en ambos casos ese año. La del BID, aprobada en marzo de 2010, fue menos ambiciosa (cerca del 70\%), ocurrió gradualmente y fue inferior a la esperada por los países latinoamericanos y caribeños. La del Banco Mundial tuvo lugar en abril de 2010, fue aún más modesta y formó parte, además, de un conjunto de reformas orientadas a aumentar la participación de los países con economías emergentes y en desarrollo en el capital de dicho organismo.

\footnotetext{
${ }^{25}$ Me refiero a la CAF como un banco regional, como se refleja en el número creciente de miembros y en el nuevo nombre de la institución, adoptado en 2010, aunque mantuvo las siglas de su antecesora, la Corporación Andina de Fomento.
} 
Esta respuesta contracíclica moderó, aunque ciertamente no compensó totalmente, el impacto de la fuerte caída de los flujos privados de capital hacia estos países. Otra área en la cual los bancos multilaterales de desarrollo cumplieron un papel importante fue en la provisión rápida de líneas de crédito comercial, que fueron utilizados por un conjunto amplio de bancos privados.

Dos lecciones importantes de la respuesta de los bancos multilaterales durante la crisis del Atlántico Norte son, por lo tanto, la necesidad de contar con buenos mecanismos para desembolsos rápidos durante las crisis y con una mayor automaticidad en la reposición de su capital. Una alternativa para acelerar los desembolsos que se utilizó entonces y, como veremos, se ha utilizado por algunos organismos durante la crisis actual, es permitir la reasignación de créditos ya aprobados hacia los objetivos de la emergencia. Otra podría ser posponer el servicio de la deuda con los propios organismos, una práctica que, sin embargo, podría afectar las calificaciones crediticias de los bancos.

La importancia relativa del apoyo de los bancos multilaterales de desarrollo a los países latinoamericanos ha cambiado radicalmente en las últimas décadas. El Banco Mundial jugó el papel de líder hasta la década de los ochenta. Sin embargo, como se observa en el gráfico 3, sus préstamos a la región no muestran una tendencia al aumento desde los años noventa. No obstante, el Banco Mundial ha seguido jugando un papel crítico durante las crisis, como indica el aumento de los préstamos a la región en 1998-1999 y, especialmente, en 2009-2010.

\section{Gráfico 3}

Créditos de los bancos multilaterales de desarrollo a América Latina

(En millones de dólares)

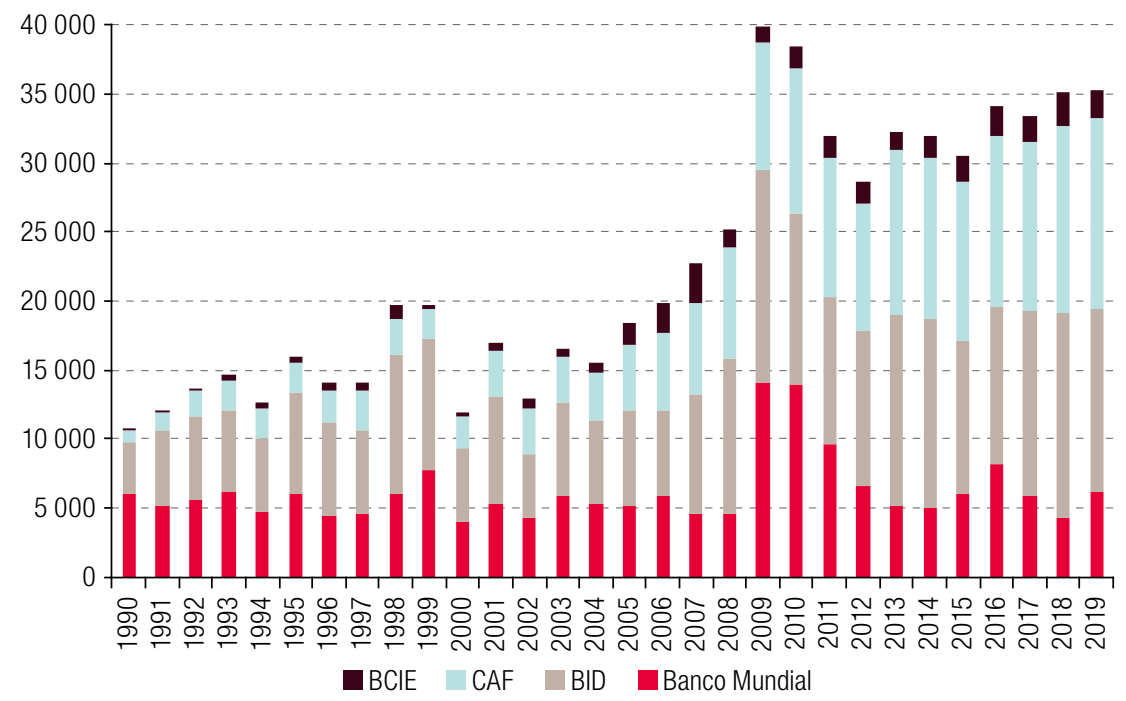

Fuente: Elaboración propia, sobre la base de datos de Banco Mundial, Banco Interamericano de Desarrollo (BID), Banco de Desarrollo de América Latina (CAF) y Banco Centroamericano de Integración Económica (BCIE).

El liderazgo mencionado pasó al BID en los años noventa antes del rápido crecimiento de la CAF y el BCIE. La dinámica de la CAF ha sido particularmente importante y ha suministrado tantos créditos como el BID en el último lustro. Aunque el BCIE es una institución más pequeña, tiene una importancia especial para los países centroamericanos y ha venido compitiendo con el BID en épocas recientes como principal fuente de financiamiento de la subregión.

Debe anotarse, sin embargo, que la capacidad de respuesta del Banco Mundial y el BID a la crisis de 2008-2009 fue mucho más agresiva que la de la CAF y el BCIE. Esto indica que, durante períodos de crisis, el apoyo implícito de los países desarrollados, en particular de los Estados Unidos, facilita el acceso a los mercados de capitales en condiciones ventajosas. Por el contrario, la CAF y el 
BCIE pueden verse afectados, al menos parcialmente, por el cierre de los mercados de capitales para las economías emergentes durante estos períodos. Cabe señalar, sin embargo, que ambos bancos se unieron a la oleada reciente de emisiones de bonos latinoamericanos.

Como muestra el cuadro 6, en términos de capital autorizado y patrimonio, la CAF fue el banco que tuvo el mayor crecimiento entre 2007 (antes del estallido de la crisis de entonces) y 2019. Tanto la CAF como el BCIE fueron capitalizados más temprano que el Banco Mundial y el BID durante la crisis. En 2018 se aprobó una nueva capitalización del Banco Mundial: un aumento del capital pagado del Banco Internacional de Reconstrucción y Fomento (BIRF) de 7.500 millones de dólares y de la Corporación Financiera Internacional (CFI) de 5.500 millones de dólares. Además, como un todo, el capital de la CFI ha crecido mucho más que el del BIRF desde la crisis de 2008-2009 (95\%), sobre la base, fundamentalmente, de la reinversión de utilidades. A su vez, en diciembre de 2019 se aprobó un aumento del capital del BCIE de 5.000 a 7.000 millones de dólares, que se hizo oficial en abril, con lo cual supera ahora a la CAF en términos de crecimiento de capital desde 2007.

Cuadro 6

Capital autorizado y patrimonio de los bancos multilaterales de desarrollo que apoyan a América Latina, 2007-2019

(En millones de dólares y porcentajes)

\begin{tabular}{|c|c|c|c|c|c|c|c|c|}
\hline & \multicolumn{4}{|c|}{ Capital autorizado } & \multicolumn{4}{|c|}{ Patrimonio } \\
\hline & BIRF & $\mathrm{BID}$ & CAF & $\mathrm{BCIE}$ & BIRF & BID & CAF & BCIE \\
\hline 2007 & 189801 & 100953 & 5000 & 2000 & 39926 & 20353 & 4127 & 1636 \\
\hline 2008 & 189801 & 100938 & 10000 & 2000 & 41548 & 19444 & 4554 & 1708 \\
\hline 2009 & 189918 & 104980 & 10000 & 5000 & 40037 & 20674 & 5287 & 1813 \\
\hline 2010 & 189943 & 104980 & 10000 & 5000 & 37555 & 20960 & 5753 & 1929 \\
\hline 2011 & 193732 & 104980 & 10000 & 5000 & 39683 & 19794 & 6351 & 2028 \\
\hline 2012 & 205394 & 116880 & 10000 & 5000 & 36685 & 20681 & 6865 & 2142 \\
\hline 2013 & 223181 & 128781 & 10000 & 5000 & 39523 & 23550 & 7817 & 2268 \\
\hline 2014 & 232791 & 144258 & 10000 & 5000 & 38985 & 23697 & 8763 & 2396 \\
\hline 2015 & 252821 & 156939 & 15000 & 5000 & 38637 & 25253 & 9524 & 2573 \\
\hline 2016 & 263329 & 170940 & 15000 & 5000 & 37063 & 26460 & 10474 & 2723 \\
\hline 2017 & 268937 & 170940 & 15000 & 5000 & 39798 & 32247 & 11122 & 2831 \\
\hline 2018 & 274730 & 170940 & 15000 & 5000 & 41844 & 32929 & 11863 & 3198 \\
\hline 2019 & 279953 & 170940 & 15000 & 5000 & 42115 & 33871 & 12797 & 3300 \\
\hline \multicolumn{9}{|c|}{ Crecimiento } \\
\hline 2007-2019 & $47,5 \%$ & $69,3 \%$ & $200,0 \%$ & $150,0 \%$ & $5,5 \%$ & $66,4 \%$ & $210,1 \%$ & $101,8 \%$ \\
\hline
\end{tabular}

Fuente: Elaboración propia, sobre la base de datos de Banco Internacional de Reconstrucción y Fomento (BIRF), Banco Interamericano de Desarrollo (BID), Banco de Desarrollo de América Latina (CAF) y Banco Centroamericano de Integración Económica (BCIE).

Todos los bancos que prestan servicios a la región han adoptado medidas especiales de apoyo durante la actual crisis: líneas especiales para enfrentar la crisis, de aprobación acelerada, aunque con recursos modestos; aumento del tamaño del programa crediticio, dentro de sus restricciones de capital; agilización en la aprobación de créditos; y, en varios casos, la posibilidad de reasignar los créditos ya aprobados a las necesidades de la emergencia.

De acuerdo con la presentación del Presidente del Banco Mundial ante el Comité Ministerial Conjunto de las Juntas de Gobernadores del Banco y del Fondo para la Transferencia de Recursos Reales a los Países en Desarrollo (Comité para el Desarrollo) del 17 de abril de 2020, el programa para hacer frente a la crisis se basa en tres pilares: i) proteger a los hogares más pobres y vulnerables; ii) respaldar a las empresas y preservar el empleo, y iii) ayudar a los países en desarrollo a implementar operaciones sanitarias de emergencia y fortalecer la resiliencia económica (Banco Mundial, 2020d). Dos elementos importantes de los paquetes anunciados son el peso significativo de los recursos destinados a los 
países de bajos ingresos - corrigiendo así uno de los problemas de las acciones del Banco durante la crisis de hace una década-y el énfasis en las medidas orientadas al sector privado a través de la CFI, ofreciendo préstamos para el comercio internacional, apoyo para capital de trabajo y financiamiento a mediano plazo a empresas privadas que deben hacer frente a rupturas de las cadenas de suministro.

El paquete de apoyo inmediato aprobado por el Banco Mundial a mediados de marzo puso a disposición de los países 14.000 millones de dólares de financiamiento nuevo en forma acelerada. Los recursos del mecanismo acelerado beneficiaron ya en abril y mayo a seis países latinoamericanos -Argentina, el Ecuador, El Salvador, Honduras, el Paraguay y el Uruguay -, aunque con recursos modestos, que en total suman 135 millones de dólares (con créditos de 20 millones de dólares, excepto el de la Argentina que fue de 35 millones de dólares).

Más allá del programa de emergencia, el Banco Mundial aprobó a fines de marzo de 2020 un paquete de 160.000 millones de dólares para los siguientes 15 meses. Este monto implica un aumento sustancial respecto del promedio anual de préstamos de 64.400 millones de dólares en 2009-2010. Este paquete más amplio incluye préstamos de emergencia y la posible reasignación de recursos de proyectos existentes. Del paquete más amplio ya se han beneficiado cinco países latinoamericanos en abril y mayo: Bolivia (Estado Plurinacional de), Colombia, Honduras, Panamá y la República Dominicana. Junto con los créditos de emergencia, América Latina ha recibido, por lo tanto, aprobaciones de créditos del Banco Mundial por 1.119 millones de dólares en abril y mayo, que superan el promedio mensual del último lustro, pero se encuentran por debajo del promedio mensual de los montos aprobados para la región en 2009-2010.

Conviene resaltar que el Presidente del Banco Mundial expresó en marzo de 2020 a los ministros de finanzas del G20 la necesidad de vincular la política de recuperación a las reformas estructurales, al decir que "Es necesario que los países pongan en marcha reformas estructurales para reducir el tiempo de recuperación y generar la confianza de que los niveles de recuperación pueden llegar a ser elevados" (Banco Mundial, 2020e). Esta asociación con las reformas estructurales es desafortunada, dado el rechazo creciente de una parte importante de los países con economías emergentes y en desarrollo a esta visión, y la escasa relación que tiene con la emergencia económica.

El programa anunciado por el BID para hacer frente a la crisis partió del principio de que el coronavirus afecta no solo la salud sino también la economía, la supervivencia de muchas empresas, las finanzas de las familias, y de que, sin un adecuado manejo, puede crear una crisis social. Estableció cuatro prioridades para sus programas de apoyo: i) respuestas inmediatas de salud pública; ii) redes de seguridad para poblaciones vulnerables, específicamente medidas para proteger los ingresos de las poblaciones más afectadas a través de los programas de transferencias existentes, así como transferencias extraordinarias a trabajadores en el sector informal y a empresas en sectores afectados por la crisis; iii) asistencia a las pymes, a través de programas de financiamiento y garantías de liquidez, financiamiento de comercio exterior, reestructuración de préstamos y apoyo a cadenas de suministro estratégicas, y iv) políticas fiscales para mejorar el impacto económico mediante el apoyo a los países en el diseño e implementación de medidas fiscales para financiar la respuesta a la crisis, planes para la ejecución de gastos y compras públicas, y medidas para contribuir a la recuperación económica.

El programa incluye un ajuste de sus programas de préstamos y una agilización de los procesos de aprobación. En términos de recursos, incluye la asignación de 3.200 millones de dólares adicionales al programa inicialmente estipulado de préstamos para 2020. Estos recursos, sumados a los recursos programados disponibles para este año, ponen a disposición de los países hasta 12.000 millones de dólares. Este monto sería, sin embargo, muy similar al promedio anual de créditos del último lustro, por lo cual, más que el monto, lo prioritario ha sido la reasignación de los recursos y la aceleración de las aprobaciones de préstamos, que han aumentado de 2.600 a 3.700 millones de dólares en los primeros cinco meses de 2020 en relación con el año anterior. En forma inmediata, ha ofrecido a los países, además, la posibilidad de reasignar recursos de préstamos ya aprobados a las nuevas prioridades 
que genera la emergencia, por un monto equivalente al 10\% de cada préstamo o hasta 50 millones de dólares (el monto que resulte mayor). La cartera privada de BID Invest (ex Corporación Interamericana de Inversiones), el brazo del sector privado del Grupo BID, ha contribuido con otros 5.000 millones de dólares e incluye líneas de apoyo a la financiación de las cadenas productivas y el comercio, y de respaldo a los bancos en un contexto de graves restricciones de liquidez.

A todo ello se agregan los recursos de cooperación técnica, tanto propios como de socios no regionales, que dan prioridad a plataformas de intercambio y aprendizaje. Los análisis de los efectos y alternativas para hacer frente a las distintas dimensiones de la crisis, que se publican en el blog del BID "Ideas que cuentan", han sido también muy importantes.

Por su parte, la CAF está ayudando en la emergencia mediante cuatro acciones concretas. La primera es una línea de crédito contingente aprobada a comienzos de marzo, de hasta 300 millones de dólares (hasta 50 millones de dólares por país) para responder de manera ágil a las necesidades de los sistemas de salud pública. La segunda es una línea de crédito de emergencia de rápido desembolso aprobada a fines de marzo de hasta 2.500 millones de dólares, para agilizar la aprobación de operaciones que apoyen las medidas de emergencia que están adoptando los países. La tercera es la posibilidad de reprogramar créditos existentes, permitiendo incluso cambiar el objetivo y el destino de los mismos. La cuarta es la prioridad dada a trabajar junto con los bancos nacionales de desarrollo para apoyar a las pymes. No es claro, sin embargo, que la CAF pueda aumentar sus créditos en forma sustancial por encima de los elevados niveles que se alcanzaron en 2018-2019 sin una capitalización adicional. En todo caso, ha acelerado también la aprobación de créditos en los primeros cinco meses de año, a 3.900 millones de dólares en comparación con 2.300 millones de dólares en 2019. A esto se agregan los recursos de cooperación técnica no reembolsables por hasta 400.000 dólares por país, que ya han beneficiado a varios miembros.

Finalmente, el BCIE lanzó el 31 de marzo de 2020 su Programa de Emergencia de Apoyo y Preparación ante el COVID-19 y de Reactivación Económica por un valor de 1.960 millones de dólares. En materia crediticia, incluye tres componentes: 1.000 millones de dólares en créditos para apoyar la gestión de liquidez de los bancos centrales de miembros regionales fundadores y no fundadores ${ }^{26}$, 600 millones de dólares de apoyo presupuestario de emergencia y 350 millones de dólares de apoyo a la liquidez del sector financiero de los países con el objetivo de sostener a las mipymes. Cabe resaltar que, a diferencia del BID y la CAF, la capitalización reciente de la entidad y el bono emitido a fines de abril le permitirán aumentar significativamente los créditos, hasta unos 3.000 millones de dólares, lo que implica un crecimiento de un $45 \%$ en relación con el promedio alcanzado durante el último lustro.

Cabe resaltar que, en ausencia de capitalizaciones adicionales del BID y la CAF - los dos bancos multilaterales más importantes que apoyan a América Latina-, los recursos suministrados por estas instituciones a los países de la región aumentarán en forma modesta en comparación con la respuesta a la crisis del Atlántico Norte, pese a que la crisis actual es más acentuada. La excepción notable es el BCIE. Por este motivo, las acciones en este campo, como en el frente monetario, deben reforzarse sustancialmente para hacer frente a los graves problemas económicos y sociales generados por la pandemia de coronavirus.

\section{Conclusiones}

La crisis económica en curso será recordada, no solo por ser la peor desde la Gran Depresión y porque las políticas internas adoptadas por los países desarrollados han sido ambiciosas, sino también por la limitada cooperación financiera multilateral acordada. Esto es cierto, en particular, respecto de las

\footnotetext{
${ }^{26}$ Los miembros regionales fundadores son: Costa Rica, El Salvador, Guatemala, Honduras y Nicaragua, y los regionales no fundadores son: Belice, Panamá y la República Dominicana.
} 
medidas para apoyar a las economías de renta media. Las acciones en favor de los países de más bajos ingresos han sido más importantes, pero también insuficientes. Ciertamente, la acción multilateral ha estado muy lejos del compromiso de hacer lo que fuera necesario, que asumieron los Líderes del G20 a fines de marzo de 2020.

En materia de cooperación monetaria internacional, lo más frustrante ha sido el rechazo a la emisión de DEG del FMI, la falta de una decisión e incluso de propuestas para avanzar hacia el aumento de cuotas del FMI, la ausencia de medidas colectivas para hacer frente a la fuga de capitales de las economías emergentes y frenar la rebaja de las calificaciones de riesgo de las agencias calificadoras. Los países latinoamericanos se han beneficiado de las líneas de emergencia del FMI, aunque con recursos modestos, así como del acceso a líneas de crédito flexible (en el caso de cuatro países), y pueden acudir a otros instrumentos de ese organismo si así lo desean. Los ocho países miembros del FLAR tienen también la posibilidad de acceder al apoyo de este organismo regional, pero sería conveniente autorizar, al menos temporalmente, que los fondos se puedan usar con propósitos fiscales. La crisis debe dar lugar también a una iniciativa para ampliar el número de miembros de este organismo regional.

En materia de deuda externa, lo conveniente es un enfoque diverso que apoye reestructuraciones ambiciosas de la deuda externa de los países que las necesiten (la Argentina y el Ecuador) y la creación de un mecanismo voluntario y supervisado multilateralmente para la suspensión del servicio de la deuda de las economías que lo requieran. Por otra parte, la recuperación temprana del mercado de deuda de las economías emergentes desde mediados de abril es una buena noticia y ha permitido a varios países y empresas públicas el acceso a financiamiento privado, así como a la CAF y al BCIE. Cabe agregar que, más allá de las medidas de corto plazo, es esencial poner nuevamente sobre la mesa la necesidad de negociar la creación de un mecanismo institucional para la renegociación de las deudas soberanas.

Los bancos multilaterales de desarrollo han creado varias líneas de emergencia para enfrentar la crisis, han agilizado sus procedimientos y varios de ellos han permitido recanalizar algunos créditos ya aprobados para hacer frente a las emergencias sanitaria, social y económica generadas por la pandemia de coronavirus. En el caso de América Latina, lo más destacable es la dinámica del BCIE, apoyada por una capitalización reciente. El Banco Mundial también ha aumentado sus créditos a la región, aunque permanecen por debajo de los que esta institución financió durante la crisis previa. Los dos principales bancos multilaterales para la región, el BID y la CAF, también han tomado medidas importantes, pero se encuentran en su límite de capacidad crediticia y necesitan ser capitalizados para apoyar en forma más firme a los países de la región durante la crisis. Como un todo, en términos de recursos, los apoyos de los bancos multilaterales a los países latinoamericanos programados son hasta ahora insuficientes.

Cabe recordar, finalmente, que los problemas económicos de un conjunto amplio de países latinoamericanos ya eran agudos durante el lustro previo a la crisis actual, y que el lento crecimiento durante esos años frenó y revirtió, en parte, la mejora en los indicadores sociales que se había experimentado desde comienzos del siglo. El crecimiento económico de la región ha sido, además, lento en las tres últimas décadas, y la región sigue estando caracterizada por múltiples problemas sociales, entre ellos tener una de las peores distribuciones del ingreso del mundo. La crisis dejará, además, un legado adverso en materia de crecimiento de la economía y el comercio mundiales y menos oportunidades para los migrantes latinoamericanos, entre otros efectos negativos.

Por lo tanto, más allá de la crisis, es necesario reformular la estrategia de desarrollo de la región, algunos de cuyos elementos deben ser el decidido impulso al desarrollo científico y tecnológico, la reindustrialización, un apoyo firme y despolitizado a la integración regional, un sólido compromiso respecto de la reducción de la desigualdad y una importante contribución a los esfuerzos mundiales de lucha contra el cambio climático y la protección de la biodiversidad. En todos estos temas, que exceden los objetivos de este análisis, el apoyo del sistema de bancos de desarrollo será también crítico. 


\section{Bibliografía}

Baldwin, R. y B. Weder di Mauro (eds.) (2020), Mitigating the COVID Economic Crisis: Act Fast and Do Whatever It Takes, Londres, Centro de Investigación sobre Políticas Económicas (CEPR).

Banco Mundial (2020a), Commodity Markets Outlook: Implications of COVID-19 for commodities, Washington, D.C., abril.

(2020b), Informe Semestral de la Región América Latina y el Caribe: la economía en los tiempos del COVID-19, Washington, D.C., abril.

(2020c), "COVID-19 crisis through a migration lens", Migration and Development Brief, № 32 , Washington, D.C., abril.

(2020d), "Palabras de David Malpass, presidente del Grupo Banco Mundial, ante el Comité para el Desarrollo", Washington, D.C., 17 de abril [en línea] https://www.bancomundial.org/es/news/statement/2020/04/17/ world-bank-group-president-malpass-remarks-to-the-development-committee.

(2020e), "Palabras del presidente del Grupo Banco Mundial, David Malpass, en la teleconferencia de Ministros de Finanzas del G-20 sobre la COVID-19", Washington, D.C., 23 de marzo [en línea] https:// www.bancomundial.org/es/news/speech/2020/03/23/remarks-by-world-bank-group-president-davidmalpass-on-g20-finance-ministers-conference-call-on-covid-19.

Bértola, L. y J. A. Ocampo (2013), El desarrollo económico de América Latina desde la independencia, Ciudad de México, Fondo de Cultura Económica.

BID (Banco Interamericano de Desarrollo), (2020), "COVID-19: actualización de la situación en América Latina y el Caribe", Washington, D.C. [en línea] https://www.iadb.org/es/coronavirus/situacion-actual-de-la-pandemia.

Bolton, P. y otros (2020), "Necessity is the mother of invention: how to implement a comprehensive debt standstill for COVID-19 in low- and middle-income countries", Londres, Centro de Investigación en Economía y Política (CEPR), 21 de abril [en línea] https://voxeu.org/article/debt-standstill-covid-19-lowand-middle-income-countries.

Brooks, R. y J. Fortun (2020), "GMV - COVID-19 capital flow exodus from EM", Global Macro Views (GMV), $N^{\circ}$ 3830, Washington, D.C., Instituto de Finanzas Internacionales (IIF), 2 de abril.

Brown, G. y L. H. Summers (2020), "El alivio de deuda es la mejor ayuda contra la pandemia", Project Syndicate, 15 de abril [en línea] https://www.project-syndicate.org/commentary/debt-relief-most-effectivecovid19-assistance-by-gordon-brown-and-lawrence-h-summers-2020-04/spanish.

Cardoso, F. H. y otros (2020), "A roadmap for confronting COVID-19 in Latin America", Americas Quarterly, 15 de abril [en línea] https://www.americasquarterly.org/article/a-roadmap-for-confronting-covid-19-inlatin-america/.

CEPAL (Comisión Económica para América Latina y el Caribe) (2020a), "Dimensionar los efectos del COVID-19 para pensar en la reactivación", Informe Especial COVID-19, № 2, Santiago, 21 de abril.

(2020b), "El desafío social en tiempos del COVID-19", Informe Especial COVID-19, №3, Santiago, 12 de mayo.

(2019), Balance Preliminar de las Economías de América Latina y el Caribe, 2019 (LC/PUB.2019/25-P), Santiago.

Cheng, G. y otros (2018), "IMF-RFA collaboration: motives, state of play, and way forward. A joint RFA staff proposal", Discussion Paper Series, № 4, Luxemburgo, Oficina de Publicaciones de la Unión Europea, octubre [en línea] https://www.esm.europa.eu/sites/default/files/esmdiscussionpaper4.pdf.

Collins, C. and E. Truman (2020), "IMF's special drawing rights to the rescue", 10 de abril, Peterson Institute for International Economics (PIIE) [en línea] https://www.piie.com/blogs/realtime-economic-issues-watch/ imfs-special-drawing-rights-rescue.

CPB (Netherlands Bureau of Economic Policy Analysis) (s/f), "World trade monitor" [en línea] https://www. cpb.nl/en/worldtrademonitor.

FEDESARROLLO (Fundación para la Educación Superior y el Desarrollo) (2020), Prospectiva económica, L. F. Mejía, X. Cadena y M. E. Delgado (eds.), Bogotá, 30 de abril.

FMI (Fondo Monetario Internacional) (2020a), World Economic Outlook: The Great Lockdown, Washington, D.C., abril. (2020b), Global Financial Stability Report: Markets in the Time of COVID-19, Washington, D.C., 14 de abril. (2020c), "Chapter 1: policies to support people during the COVID-19 pandemic", Fiscal Monitor, Washington, D.C., 15 de abril. 
(2020d), "Press briefing by Kristalina Georgieva following a conference call of the International Monetary and Financial Committee", Washington, D.C., 27 de marzo [en línea] https://www.imf.org/en/News/ Articles/2020/03/27/tr032720-transcript-press-briefing-kristalina-georgieva-following-imfc-conference-call. (2020e), "The managing director's global policy agenda, spring meetings 2020: exceptional times, exceptional action", Policy Papers, № 20/020, Washington, D.C., 14 de abril.

(2020f), "IMF Primary Commodity Prices", junio [en línea] https://www.imf.org/en/Research/commodity-prices. (2017a), "Collaboration between regional financing arrangements and the IMF", Policy Papers, Washington, D.C., 31 de julio.

(2017b), "Adequacy of the global financial safety net - Considerations for fund toolkit reform", Policy Papers, Washington, D.C., 19 de diciembre.

(2012), "The liberalization and management of capital flows: an institutional view", Policy Papers, Washington, D.C., 14 de noviembre.

Gallagher, K. P., J. A. Ocampo y U. Volz (2020), "It's time for a major issuance of the IMF's special drawing rights", Financial Times, 20 de marzo [en línea] https://ftalphaville.ft.com/2020/03/20/1584709367000/ It-s-time-for-a-major-issuance-of-the-IMF-s-Special-Drawing-Rights/.

Gallagher, K. P. y otros (2020), "Safety first: expanding the global financial safety net in response to COVID-19", GEGI Working Paper, № 0037, Boston, Boston University, abril.

Georgieva, K. (2020), "Afrontar la crisis: prioridades para la economía mundial", Washington, D.C., Fondo Monetario Internacional (FMI), 9 de abril [en línea] https://www.imf.org/es/News/Articles/2020/04/07/ sp040920-SMs2020-Curtain-Raiser.

Griffith-Jones, S., R. Marodon y J. A. Ocampo (2020), "Mobilizing $\$ 400$ billion: using the visible hand of development banks", Center for Global Development, 10 de abril [en línea] https://www.cgdev.org/blog/ mobilizing-400-billion-using-visible-hand-development-banks.

Grupo de Personas Eminentes del G20 sobre la Gobernanza Financiera Mundial (2018), Making the Global Financial System Work for All: Report of the G20 Eminent Persons Group on Global Financial Governance, octubre [en línea] https://www.globalfinancialgovernance.org/assets/pdf/G20EPG-Full\%20Report.pdf.

G20 (Grupo de los 20) (2020a), "Extraordinary G20 Leaders' Summit: statement on COVID-19", documento presentado en la Cumbre Extraordinaria de Líderes del G20, Riad, 26 de marzo [en línea] http://www. g20.utoronto.ca/2020/2020-g20-statement-0326.html.

(2020b), "Communiqué", documento presentado en la Reunión de Ministros de Hacienda y Gobernadores de los Bancos Centrales del G20, Riad, 15 de abril [en línea] http://www.g20.utoronto.ca/2020/2020g20-finance-0415.html.

(2009), "Global Plan for Recovery and Reform", documento presentado en la Cumbre de Líderes del G20, Londres, 2 de abril [en línea] http://www.g20.utoronto.ca/2009/2009communique0402.html.

Izquierdo, A. y M. Ardanaz (2020), "Política fiscal en tiempos del coronavirus: restricciones y opciones de política para los países de América Latina y el Caribe", Ideas que Cuentan, Banco Interamericano de Desarrollo (BID), 31 de marzo [en línea] https://blogs.iadb.org/ideas-que-cuentan/es/politica-fiscal-entiempos-del-coronavirus-restricciones-y-opciones-de-politica-para-los-paises-de-america-latina-y-el-caribe/.

JP Morgan (2020), EMFlows Weekly, 28 de mayo.

Levy, S. (2020), "Sugerencias para la emergencia", COVID-19. Serie de Documentos de Política Pública, $N^{\circ}$ 2, Nueva York, Programa de las Naciones Unidas para el Desarrollo (PNUD), marzo.

Maddison, A. (2010), "Maddison database 2010", Groningen Growth and Development Centre, Universidad de Groningen [base de datos en línea] https://www.rug.nl/ggdc/historicaldevelopment/maddison/releases/ maddison-database-2010.

Mnuchin, S. (2020), “U.S. Treasury Secretary Steven T. Mnuchin's Joint IMFC and Development Committee Statement", Departamento del Tesoro de los Estados Unidos, 16 de abril [en línea] https://home.treasury. gov/news/press-releases/sm982.

Naciones Unidas (2020), La deuda y la COVID-19: una respuesta global solidaria, Nueva York, 17 de abril [en línea] https://www.un.org/sites/un2.un.org/files/informe-deuda-covid-19.pdf.

Nuguer, V. y A. Powell (coords.) (2020), "Políticas para combatir la pandemia", Informe Macroeconómico de América Latina y el Caribe, Washington, D.C., Banco Interamericano de Desarrollo (BID), abril.

Ocampo, J. A. (2020), “¿Puede América Latina evitar otra década perdida?”, Project Syndicate, 3 de enero [en línea] https://www.project-syndicate.org/commentary/latin-america-lost-decade-low-growth-by-joseantonio-ocampo-2020-01/spanish?barrier=accesspaylog. 
(2017), Resetting the International Monetary (Non)System, Oxford, Oxford University Press.

Ocampo, J. A. y otros (2011), "La gran recesión y el mundo en desarrollo", Cooperación para el desarrollo en tiempos de crisis, J. A. Alonso y J. A. Ocampo (coords.), Ciudad de México, Fondo de Cultura Económica.

OMC (Organización Mundial del Comercio) (2020), "Desplome del comercio ante la pandemia de COVID-19, que está perturbando la economía mundial”, Comunicado de Prensa (Press/855), Ginebra, 8 de abril [en línea] https://www.wto.org/spanish/news_s/pres20_s/pr855_s.pdf.

Pineda, E., C. Pessino y A. Rasteletti (2020), "Política y gestión fiscal durante la pandemia y la post-pandemia en América Latina y el Caribe”, 21 de abril [en línea] https://blogs.iadb.org/gestion-fiscal/es/politica-ygestion-fiscal-durante-la-pandemia-y-la-post-pandemia-en-america-latina-y-el-caribe/.

Reinhart, C. y K. Rogoff (2020), "Una moratoria a las deudas de economías emergentes y en desarrollo", Project Syndicate, 13 de abril [en línea] https://www.project-syndicate.org/commentary/suspend-emergingand-developing-economies-debt-payments-by-carmen-reinhart-and-kenneth-rogoff-2020-04/spanish.

Stiglitz, J. E. y otros (2020), "How the economy will look after the coronavirus pandemic", Foreign Policy, 15 de abril [en línea] https://foreignpolicy.com/2020/04/15/how-the-economy-will-look-after-the-coronavirus-pandemic/.

Tooze, A. (2020), "The coronavirus is the biggest emerging markets crisis ever", Foreign Policy, Washington, D.C., 28 de marzo [en línea] https://foreignpolicy.com/2020/03/28/coronavirus-biggest-emerging-marketscrisis-ever/.

UNCTAD (Conferencia de las Naciones Unidas sobre Comercio y Desarrollo) (2020a), "The COVID-19 shock to developing countries: towards a 'whatever it takes' programme for the two-thirds of the world population being left behind", Trade and Development Report Update (UNCTAD/GDS/INF/2020/2), Ginebra, marzo. (2020b), "From the great lockdown to the great meltdown: developing country debt in the time of COVID-19", Trade and Development Report Update (UNCTAD/GDS/INF/2020/3), Ginebra, abril. 